\title{
Miguel de Unamuno, tragedia y esperanza. ¿Qué debemos hacer y qué podemos esperar?
}

José Mendívil Macías Valadez

Universidad de Guanajuato

\begin{abstract}
From Miguel de Unamuno's perspective, we would be left with no more than a quixotic faith dying in the face of the finite and contingent condition of life - caught up in tragedy and hope. Analyzing this kind of pragmatic creative vitalism, this paper aims to link the vital imperatives with the following Kantian questions: "What Should I Do and What Can I Hope?", to find, in spite of the differences, the possibility of ethics imperatives in Unamuno's view: to be unique, to deserve the eternity and feel a compassionate solidarity with the Other in the middle of indigence and helplessness, individual as well as social and political imperatives.
\end{abstract}

Keywords: Unamuno, ethics, politics, tragedy, faith, hope, creationism, compassion, solidarity.

\section{Resumen}

Para Unamuno, en la vida sólo nos quedaría una quijotesca fe agónica frente a nuestra finitud contingente de vivir entre la tragedia y la esperanza. En el análisis de esta especie de vitalismo creativo pragmático, se busca relacionar los imperativos vitales con las preguntas kantianas: ¿qué debo hacer y qué puedo esperar? con el fin de encontrar, a pesar de las diferencias, la posibilidad de imperativos éticos en Unamuno: el imperativo de ser único, el de merecer la eternidad y el de la solidaridad compasiva con el otro en la indigencia y el desvalimiento, imperativos individuales tanto como sociales y políticos.

Palabras clave: Unamuno, ética, política, tragedia, fe, esperanza, creacionismo, compasión, solidaridad. 
$\mathrm{E}^{\mathrm{n}}$ n su libro sobre Miguel de Unamuno, Pedro Ribas caracteriza al filósofo de Bilbao afirmando que "reclama el derecho de expresión del individuo, de la persona individual, del yo" (2002: 212). Aquí intentaré mostrar el planteamiento ético que acompaña a esta reclamación del derecho a la individualidad singular.

El punto de partida de Unamuno, como el de Kierkegaard, es el "hombre concreto, de carne y hueso", sujeto y supremo objeto a la vez de toda filosofía, "quiéranlo o no ciertos sedicentes filósofos" (Unamuno, 1966). Estos filósofos sedicentes serían aquellos que no habrían entendido que la filosofía es algo que se vive y no una serie de abstracciones o conocimientos aislados de la existencia; aunque la vida del hombre concreto, en Unamuno como en Pascal, no puede ser sino contradicción, incertidumbre y angustia, por ello es el sentimiento trágico de la vida el que produce una concepción trágica, y nunca al revés. Pero, ¿̨de dónde viene este sentimiento trágico? De la contradicción y la oposición entre el corazón y la razón, un corazón que quiere vivir y exige eternidad, y una razón cientificista que no puede asegurárnosla, de aquí surge la esperanza como una necesidad intrínsecamente humana, unida a la lucha entre la duda y la convicción. La tragedia personal reside, para Unamuno, en el conflicto irresoluble entre la razón y la fe entendida como esperanza, que sin embargo no nos priva de la angustia y de la incertidumbre.

Esta conciencia trágica parte de una verdad vital, sostenida por el filósofo vasco pero ya constatada por Spinoza: que todos deseamos, en lo posible, perseverar en nuestro ser, pues un rasgo esencial del hombre consiste en este esfuerzo por seguir siendo hombre, por no morir (Unamuno, 1966). Este sentimiento por perseverar acabaría exigiendo la eternidad completa, la cual no se podría satisfacer con la inmersión en una totalidad en la que se preserven nuestros átomos, ni en una totalidad panteísta, puesto que deseamos preservarnos tal como somos, en nuestro ser completo. A diferencia de Spinoza, Unamuno piensa que el pensamiento de la muerte es ineludible e, incluso, 
un deber. Los hombres y los pueblos entran en la pubertad — maduran-cuando la descubren. Ni la gloria de las estatuas erigidas, ni las grandes tumbas, ni la descendencia, ni la memoria patriótica pueden hacernos escapar de la mortalidad. Tampoco la autoafirmación egoísta y envidiosa nos sirve de nada frente a este desesperante destino. $\mathrm{Ni}$ los científicos ni los escolásticos han podido justificar racionalmente nuestra supervivencia. La fe no ha dejado, para Unamuno, de ser algo gratuito, trascendente e irracional.

Al no haber reconciliación posible, sólo nos quedaría una fe agónica (agonía significa precisamente lucha) ubicada en nuestro corazón y en nuestras entrańas, visceral y cardiaca, centrada en un vitalismo heroico, en un cristianismo quijotesco cuya fe no consiste en creer en lo que no vemos, sino en crear lo que vemos, (Unamuno, 1966: 261) la fe es una creación vital. Unamuno resuelve de manera muy peculiar la crisis religiosa que, como un terremoto, le acomete en 1897, crisis de la que nunca se recuperará, intentando una salida con la idea de que, finalmente, la fe crea su propio objeto. "La fe se alimenta del ideal [...] pero de un ideal real, concreto, viviente, encarnado, y a la vez inasequible; la fe busca lo imposible, lo absoluto, lo infinito y lo eterno: la vida plena. Fe es comulgar con el universo todo, trabajando en el tiempo para la eternidad" (262). De este modo el anacoreta debería dejar ya de renegar del mundo y de la vida, para poder "derramarse en la vida común y vivir con la vida de todos" (265) en una entrega amorosa, sincera, tolerante y misericordiosa. La fe es una forma de dar sentido y finalidad a una vida azarosa, absurda e irracional, que va de la nada a la nada.

El sentimiento religioso de Unamuno procede por vía negativa, nace de un vacío y un ansia, del hambre y la carencia de Dios. De esta experiencia de la nada y de la finitud, surgiría esta necesidad. Creer en Dios no es más que "querer que haya Dios", se trata de la voluntad de creer. No es fácil de explicar cómo un hombre que se describe, en el prólogo de sus Soliloquios, como un "cartujo laico, ermitaño civil y 
agnóstico, acaso desesperado de esta vieja España”, acaba siendo un sufrido partidario de la esperanza religiosa. Finalmente, el pragmatismo juega un papel interesante en este voluntarismo, cercano a Duns Scoto, y en este cierto aire protestante. Abbagnano (1973: 527), en su Historia de la filosofía le llama un fideísta pragmático contemporáneo, en el sentido de que subordina el conocimiento y la razón a la vida y a la acción, puesto que algo acaba siendo verdad por el impulso que da a la vida, la filosofía nacería de un sentimiento vital, como dice Unamuno en su Vida de don Quijote y Sancho:

La vida es el criterio de la verdad, y no la concordia lógica [...] Si mi fe me lleva a crear o aumentar vida, ¿para qué queréis más prueba de mi fe? [...] Si caminando moribundo de sed ves una visión de eso que llamamos agua, y te abalanzas a ella y bebes, y aplacándote la sed te resucita, aquella visión lo era verdadera y el agua de verdad. Verdad es lo que moviéndonos a obrar de un modo o de otro haría que cubriese nuestro resultado a nuestro propósito (Unamuno, 1966).

Se trata de una tesis inspirada, entre otras fuentes, en el pragmatista norteamericano W. James, según la cual se convierten en "verdaderas" las creencias que son útiles para la acción, e incluso en la invocación de James a la apuesta de Pascal, puesto que toda creencia comportaría un riesgo que sin embargo hay que correr. Por supuesto que el "quijotismo" de Unamuno va más allá de estas tesis, puesto que parte además de una peculiar posición historicista que pretendió encender en el pueblo español lo que él veía como las eternas inquietudes espirituales que subyacen en el fondo de sus tradiciones, en la "intrahistoria" como sustrato eterno e inconsciente.

Se ha escrito mucho acerca de las ambivalencias de Unamuno en relación con la necesidad de una modernización y europeización de España, que él veía con desconfianza en caso de no ir acompañada de una paralela españolización de Europa, pero lo cierto es que él 
quería, además de acabar con los tiranos y los monarcas autoritarios, rescatar este sustrato del espíritu español que veía condensado en la figura de don Quijote, para quien "sólo el que ensaya lo absurdo es capaz de conquistar lo imposible" (Unamuno, 1966). Cualquiera de las dos Espańas que triunfase, y que en su momento disputaron su apoyo, debería de hacerlo sobre la base de este idealismo quijotesco. Hasta qué punto esta aceptación de la tradición española lo llevará en ocasiones a una falta de espíritu crítico, será siempre un tema polémico que no puedo agotar aquí.

Sin embargo, uno de los aspectos interesantes que quiero señalar, es que el tipo de reflexiones de Unamuno acerca de la incertidumbre de la vida y de la propia esperanza podrían llevar a la descreencia tanto como a la creencia, puesto que ignoraríamos si somos mortales o inmortales. El deseo trágico de la inmortalidad puede ser compartido por el ateo, sacando del mismo hecho otras conclusiones o aspiraciones, como en su momento hicieron Sartre, Camus, o el propio Abbagnano: "La incertidumbre es propia también, incluso más propia, del que no cree; y si sólo la incertidumbre es vital, ninguna diferencia pragmática subsiste verdaderamente entre quien afirma o niega la inmortalidad" (1973: 529).

Pero al margen de los "parecidos de familia" entre los distintos existencialismos, me interesa analizar críticamente cómo puede surgir una ética y un compromiso social a partir de estos exiguos supuestos, es decir, partiendo de la carencia, la contingencia, la ausencia y el dolor. ¿Qué podemos esperar? ¿Qué debemos hacer? Estas preguntas que Kant invocó están, sin embargo, relacionadas con otra: ¿Qué es el hombre? Por supuesto que no podría Unamuno quedarse con el hombre nouménico, volitivo e ideal, sino que intentaría rescatar al de carne y hueso, pero que también sueña, imagina y espera. Este hombre no es el yo solitario, aunque éste sea el punto de vista que le agrada más elegir, sino el nosotros en situación. "Es mejor decir nosotros. Pero nosotros los circunscritos en espacios" (529). 
La construcción del yo y del nosotros en Unamuno, como en el caso de la fe, también tiene que ver con lo que queremos ser, se trata también de una invención. El hombre más real sería el que quiere ser creador, de allí que la novela sea un buen instrumento de autoconocimiento. La relación entre la humanidad y Dios también puede entenderse en Unamuno en un sentido similar al de Feuerbach, Dios es un anhelo humano, una proyección de sí mismo, "la creencia en un Dios personal y espiritual se basa en la creencia en nuestra propia personalidad y espiritualidad" (Unamuno, 1966). El hombre sólo podría ser un hombre hecho y derecho "cuando quiere ser más que hombre"; "el que quieres ser es tu idea en Dios" (Unamuno, 1966), de esta manera Dios es el ideal de la humanidad, el hombre proyectado al infinito y eternizado en Él, pero una humanidad que se concretiza en individuos, "amor que no cuaja sobre individuo, no es amor de verdad" (Unamuno, 1966).

En el ensayo titulado Soledad (1966), Unamuno, el pensador bilbaíno, afirma que a pesar de que los hombres parecemos impenetrables, nos comunicamos por contacto a pesar de nuestra dura costra, es decir, mediante el "choque mutuo", que implica entre otras cosas, sentir dolor, o experiencias como los gemidos del prójimo. También la soledad meditativa nos ayudaría a adelgazar nuestro caparazón y a socializarnos. En el diálogo interior uno podría conocerse a sí mismo como prójimo. Finalmente, los grandes solitarios acabarían siendo los más sociales, y los genios una muchedumbre individualizada.

Como dice Unamuno en la voz de su personaje, el doctor Montarco, existiría en los hombres, además de un instinto de conservación que nos impele a permanecer, un "instinto de invasión", puesto que querríamos siempre excedernos y sobrepasarnos, ser más, serlo todo, por eso tendríamos un apetito de divinidad, para ser como dioses. De modo que una de las paradojas del sentimiento trágico de la vida es que, por un lado, existiría el deseo de ser uno mismo en su autenticidad propia, y por otro nos desbordamos hacia los demás y hacia la 
totalidad del universo: "quiero ser yo, y sin dejar de serlo, ser además los otros, adentrarme a la totalidad de las cosas [...] extenderme a lo ilimitado" (Unamuno, 1966), por ello desearía ser o todo o nada.

Sin embargo, el cimiento de la relación ética con los demás se concreta a partir de la carencia, de la lucha infructuosa por salir de la incertidumbre y el dolor agónico que ésta provoca (Unamuno, 1966). El amor carnal sería una lucha trágica, a partir del egoísta afán de poseer al otro y perpetuarse, se da un desgarramiento en el que nos damos hasta morir, nos partimos hasta dejar de ser, lo que unifica a la cópula con la muerte y la sensación de resurrección. El amor espiritual nacería de la experiencia común del dolor, por ello amar es compadecer; "los hombres sólo se aman con amor espiritual cuando han sufrido juntos un mismo dolor" (Unamuno, 1966), el amor nace del afán de ayudar al desvalido, como en el caso de la madre y su hijo, pero también se compadece a lo semejante, al semejante en inanidad y desesperación, porque todos desfilamos de la nada a la nada.

Este impulso trágico por llegar a ser inmortal, que nuestro pensador ha visto también en Schopenhauer y Nietzsche, es el cimiento del amor, como lo serían también de la metafísica y de la teología. Las cosas en el universo, como los individuos, luchan y sufren por conservarse y acrecentarse, de modo que la compasión "nos revela la semejanza del universo todo con nosotros", puesto que en él proyectamos ese sentimiento, y en el caso de la relación con el prójimo, "al oírle un grito de dolor a mi hermano, mi propio dolor se despierta y grita en el fondo de mi conciencia” (Unamuno, 1966); finalmente, así nos personalizamos, puesto que amar es un requisito para ser persona. El amor, sin embargo, nos relaciona con los otros en cuanto semejantes, pero cada hombre no dejaría de ser único e insustituible, y valdría por el universo todo (Unamuno, 1966).

Fernando Savater afirma que el verdadero "imperativo categórico" de Unamuno podría ser este carácter irremplazable y único de cada uno de nosotros, puesto que considera, además, junto con Jorge 
Luis Borges, que el deseo de inmortalidad no puede ser generalizado sin reservas, puesto que no todos desearían cargar con el peso de su existencia para siempre, algunos no lo soportarían ni un día más (Savater, 1986: 11). Esto relativiza el imperativo propuesto por Unamuno de que hay que "merecer la eternidad", puesto que no todos la desean irrestrictamente. Pero entonces, ¿cabrían, además, otros deberes similares a éste, que puedan generalizarse como imperativos? Podríamos situar, con Unamuno, en el amor compasivo el origen de la sociabilidad, pero no fácilmente podríamos empatarlo con la idea kantiana del deber. A pesar de esto, ¿podríamos generalizarlo? ¿Podría ser un deber generalizado ser compasivo? Después de todo un imperativo no tiene que surgir únicamente de la razón, podría surgir, como en este caso, de la lucha de la razón con el impulso vital, un imperativo trágico y sentimental, sin duda. Analicemos de dónde nace la conciencia social en Unamuno: "Es la conciencia social, hija del amor, del instinto de perpetuación, la que nos lleva a socializarlo todo, a ver en todo sociedad, y nos muestra, por último, cuán de veras es una Sociedad infinita la Naturaleza toda" (Unamuno, 1966).

La conciencia social sería parte de este instinto de invasión en el que queremos ser todos los otros, pero también todas las cosas. La simpatía entonces se extiende al universo, se proyecta en todas las cosas, se expande románticamente desde el yo en su proyección. Finalmente, de la mezcla de este individualismo ibérico — que se origina en un pueblo de pastores - con este compromiso social nace su liberalismo crítico, unido a la causa de la justicia y de la libertad (que le costó el exilio), y que ha pasado por el Partido Socialista. Un liberalismo intuitivo y universalizado como una "religión de la libertad" (Unamuno, 1966; Díaz, 1968: 29). Liberalismo que Elías Díaz ha llamado "organicista", que ni evade la función social y la responsabilidad del Estado, ni convierte a éste en la estructura que engulle a la sociedad entera. "Los anarquistas, si quieren vivir, tienen que fundar un Estado. Y los comunistas tienen que apoyarse en la libertad indivi- 
dual [...] Los más radicales individualistas fundan una comunidad" (Unamuno, 1966), como se puede ver, se trata de la búsqueda de un equilibrio entre el individuo y la sociedad. Sin embargo, no deja de ser el suyo un pensamiento elitista y aristocratizante, propio de un hombre acusado de "egotista", (Díaz, 1968: 29 y ss.) acusación que deriva de su convencimiento de que "quien defiende y exalta su propia personalidad, su yo, defiende y exalta las personalidades, los yos de los demás" (Díaz, 1968: 31). Sin embargo, no podría dejar de ser contradictoria una postura liberal y solidaria que es al mismo tiempo antiprogresista y espiritualista, que lo llevará finalmente a una desconexión e incomprensión de la realidad social concreta ${ }^{1}$ (Díaz, 1968: 173), una realidad española que se convierte en guerra civil, tan desgarrada, trágica y agónica como su propio pensamiento.

Así, Unamuno ha tenido que asumir en política lo que asume en su pensamiento, lo ideal, lo quijotesco, lo intra-histórico y eterno. Pedro Laín Entralgo, uno de los críticos que mejor ha entendido a Unamuno, lo sitúa dentro de una característica de la generación del 98: desengañarse de los programas políticos y evadirse del presente histórico hacia el ensueño, el ideal, lo utópico y lo ucrónico, lo que en este caso se resuelve en la contradicción entre la historia y el ideal, en la búsqueda trágica de posibilidades de realización de nuestras invenciones.

\footnotetext{
${ }^{1}$ No exageraremos aquí este hiato como si fuera una desconexión total, habría que reconocer que el pensamiento de Unamuno no es ni un "idealismo" ni un "realismo" en su sentido habitual. José Ferrater Mora ha señalado la peculiaridad de la noción de "realidad" en Unamuno, que, si bien es paradójica y metafórica en su formulación, parte de lo "entrañable" (es decir, de las íntimas entrañas, del tuétano y la médula, de las honduras) y de características como lo denso, grave, abrupto, contradictorio y activo, parte en fin de una realidad que "siente, sufre, compadece y desea”, y por lo tanto, es también — pero no sólo— conciencia (Ferrater Mora, 1957, cap. VII).
} 
De modo que volvimos de nuevo a la médula y al núcleo de su pensamiento, sus ideas sociales son acordes con las ideas acerca de las relaciones intersubjetivas, y éstas acordes con su idea de Dios y del yo. En el fondo todas éstas son invenciones de la voluntad, proyecciones de la condición humana trágica, Laín Entralgo, en su libro Teoría y realidad del otro, intitula su capítulo "El creacionismo de Unamuno", y en él interpreta la relación interpersonal como una relación entre un yo inventado y la conversión del otro en "mi otro" por medio de la imaginación. Mi compasión inventaría al otro, encontrándolo como semejante — partiendo sin embargo del contacto, del dolor y de la resistencia - de este modo Unamuno "magnificó la actividad imaginativa y creadora del yo en su relación con el otro" (Laín Entralgo, 1983: 155).

En mi opinión, sin abundar en las consecuencias literarias de mi aserto, este creacionismo es similar al que enarbola el poeta chileno Vicente Huidobro, quien consideraba que el poeta es un pequeño Dios por su papel creador. Unamuno también juega a ser Dios, lo inventa con su querer, como a un universo humanizado por la compasión y la simpatía, pero va más allá porque a la vez intenta crear un mundo social abrazado por la compasión a nuestros semejantes, de modo que el proceso de amar al otro y el de crear serían uno y el mismo. La entrega al otro implicaría asumir de manera quijotesca que sólo quien se atreve a ensayar lo absurdo será capaz de conquistar lo imposible. Esta conquista de lo imprevisto y lo soñado podría ser sumado a los imperativos de Unamuno (que si no necesariamente serían categóricos, sí podrían ser hipotéticos e incluso convertirse en máximas prudenciales), junto con el de merecer la eternidad, que mezclándolo con una idea kantiana podría significar ser digno de esa eternidad, y finalmente el que yo considero el más interesante y actual de todos, el imperativo de compadecer a nuestros semejantes, que son tan indigentes y mortales como nosotros, puesto que su vida es tan incierta como la nuestra, y el desvalimiento abunda. Estos 
imperativos no podrían ser más que esperanzas para Unamuno, pero esperanzas que muchos podríamos albergar, y que no surgen de meras quimeras, sino de nuestra íntima naturaleza en tanto seres sintientes, de carne y hueso.

\section{Bibliografía}

Abbagnano, Nicola, 1973, Historia de la filosofía, vol. III, Montaner y Simón, Barcelona.

Díaz, Elías, 1968, Revisión de Unamuno. Análisis crítico de su pensamiento politico, Tecnos, Madrid.

Ferrater Mora, José, 1957, Unamuno. Bosquejo de una filosofía, Sudamericana, Buenos Aires.

Laín Entralgo, Pedro, 1947, La generación del noventa y ocho, Espasa-Calpe, Madrid.

, 1983, Teoría y realidad del otro, Alianza, Madrid.

Ribas, Pedro, 2002, Para leer a Unamuno, Alianza, Madrid.

Savater, Fernando, 1986, "Prólogo”, en Miguel de Unamuno, Del sentimiento trágico de la vida, Alianza, Madrid.

Unamuno, Miguel de, 1966, Ensayos, Aguilar, Madrid. 